\title{
English as a Lingua Franca: Lessons for language and mobility ${ }^{1}$
}

\author{
Joseph Sung-Yul Park \\ National University of Singapore, Singapore \\ Lionel Wee \\ National University of Singapore, Singapore
}

ellpsj@nus.edu.sg

\begin{abstract}
Greater mobility of people in the globalising world foregrounds the inherent problems of an ideology of language as a bounded entity and the unequal relations of power that shape experiences of mobility. In this paper, we consider how these problems can be interrelated in research on language and mobility through a critical evaluation of current research on English as a lingua franca (ELF), particularly what we refer to as the 'ELF research project', exemplified by the work of Jenkins and Seidlhofer. The ELF project aims at a non-hegemonic alternative to English language teaching by identifying a core set of linguistic variables that can facilitate communication between speakers of different linguistic backgrounds. We provide a critical examination of the project by problematising its narrow conceptualisation of communication as information transfer and its inability to address the prejudices that speakers may still encounter because they speak the language 'differently'. In our discussion, we argue that investigation of language in the context of mobility requires serious rethinking on the level of both theory and political stancetaking: a theory of language that does not take account of the fluid, dynamic, and practice-based nature of language will have considerable difficulty in proposing a cogent critique of social inequalities that permeate the lives of people on the move.
\end{abstract}

Key words: mobility, English as a lingua franca, language as bounded entity, inequalities 


\section{INTRODUCTION}

reater mobility of people in the gloJalising world leads us to reconsider many of our fundamental assumptions about language. For instance, the increasing movement of people across national borders questions boundaries between languages; and prevalent practices of hybridity and appropriation press us to problematise the notion of language as a stable, homogeneous entity. At the same time, the prominence of mobility increases the need for us to pay attention to relations of power and the way they shape such experiences of mobility. Different constraints imposed upon different mobile populations remind us that the linguistic competence and repertoire of social groups are always evaluated in the context of power, demanding greater sensitivity to the structure of inequalities that condition mobility.

One important theoretical and practical point that could be made about these two issues that are brought into relief by mobility - the ideology of language as a bounded entity and the unequal relations of power that shape experiences of mobility - is that they are interrelated. Ideologies of language that uphold assumptions of homogeneity and unity of a language community typically work to disenfranchise mobile speakers on the margin of the mainstream society. Furthermore, privileged migrants are able to benefit from their mobility more than less privileged ones, precisely because of their ability to negotiate with dominant ideologies of language that define what counts as legitimate and authentic language. Research on language and mobility that aims to address either of these two issues, then, must also seriously engage with the other as well, if it is to achieve a fuller understanding of how experiences of language and mobility mutually shape each other.
The recent debate about English as a lingua franca (ELF) provides a useful opportunity for considering this point. Over the past two decades, many researchers have focused on how English, as a global language, is now used frequently for practical purposes of international communication by and among those who are commonly seen as 'non-native speakers'. As a result, a large body of work on ELF (Canagarajah 2007; Firth 1996; House 2002, 2003; Jenkins 2000, 2006, 2007; Kirkpatrick 2010; Prodromou 2008; Seidlhofer 2001, 2005, 2006, among others) has emerged, problematising the legitimacy and authority that have been traditionally reserved for 'native speakers' of Kachruvian inner circle countries and questioning the characterisation of nonnative speakers as deficient. In this sense, ELF research is explicitly orientated towards contesting unequal relations of power that constrain social life in global communication; it is an effort to shift the centre of the hegemony of English that conditions how people on the move are perceived and evaluated.

However, among researchers working within this paradigm, there has been a heated discussion over a particular direction of research, which we call for the sake of convenience the 'ELF research project'. Here, we refer to the project centred on the work of Jennifer Jenkins (2000) and Barbara Seidlhofer (2004), which aims to identify core linguistic features that facilitate intelligibility in ELF communication so that a counterhegemonic curriculum of English language teaching may be developed. While the ELF research project has been highly influential, its tenets have also triggered much debate. Critics are concerned that such efforts to establish an ELF core has the danger of reintroducing a monolithic model of English that the notion of ELF 
is meant to contest, and that English language teaching programmes based on features of ELF may inadvertently disadvantage learners because the still dominant ideologies of language value only 'centre' varieties of English.

In this paper, we review the key issues in the debate over the ELF research project as a way of illustrating how a critical reconsideration of our assumptions about the nature of language and the need to focus on issues of inequality must go hand in hand when studying language and mobility. We suggest that the primary reason why the ELF research project has caused such controversy is that its theoretical and methodological assumptions tend to view language as a fixed, static, and clearly delineable object that can be dissociated from social relations of speakers. Because such a view cannot adequately capture the complexity and dynamism of the way ELF is used in social contexts, it leads to contradictions between the political goals of the ELF research project and what it ends up suggesting as strategies for intervention. Through our discussion, we draw lessons about how investigation of language in the context of mobility requires serious rethinking on the level of both theory and political stance-taking, arguing that a theory of language that does not take into account the fluid, dynamic, and practice-based nature of language will find it difficult to propose a cogent critique of social inequalities that permeate the lives of people on the move. In the following, we first review two main issues with the ELF research project - its methodological focus on the 'pure' form of ELF, and the implications of its emphasis on formal features of ELF. We then move on to consider their implications for engaging in responsible investigations of language and mobility.

\section{IN SEARCH OF PUREST FORM: WHO SPEAKS ELF?}

Current research on ELF is based on 4 several key assumptions. The first is that the spread of English as a global language has led to the situation in which speakers for whom English is the second language outnumber those for whom it is the first language (Crystal 1988, 2003; Jenkins 2000; Phillipson 1992). This observation about numerical superiority has led to a further claim: that the ways in which English is being used globally are increasingly varied, giving more weight to the language as used by non-native speakers. Thus, Seidlhofer suggests that English, 'as a consequence, is being shaped, in its international uses, at least as much by its non-native speakers as its native speakers' and 'the language is used more and more for practical purposes by people with very varied norms and scopes of proficiency' (2004:211-212).

The above two claims, which serve as the basic assumption for research on ELF, are for the most part uncontroversial. This is because changes in language practices can and should be reasonably expected when the language itself comes to be used by more speakers. However, these two claims have also led to a more controversial claim. This is the claim that because first-language speakers (or 'native speakers') are outnumbered, the kind of English spoken by them is supposed to be increasingly irrelevant to the use of English on the global stage.

It is this third assumption that gives specific shape to the ELF research project, leading it along a different trajectory from other researchers working on ELF. Because the English of native speakers are supposedly becoming irrelevant to many learners of English who intend to use it as a language of international communication, it follows that the model for English 
language learning should shift towards how those non-native speakers use it as a lingua franca. Thus, the objective of the ELF research project becomes providing descriptions of the ways in which English is used by non-native speakers in international contexts, so that the information gathered can serve as a basis for a language teaching approach that is more reflective of the English language's global demographic (Seidlhofer 2005: 340).

In the ELF research project, this information on English as a lingua franca is primarily information on the form of English used as such, that is its linguistic features. But since it is also obvious that ELF does not exist in a single, coherent form, being used by speakers from a wide range of linguistic, cultural, and national backgrounds, the target of the ELF research project is not description of the entire range of linguistic features that describe ELF as a linguistic variety, but identification of the most important group of features that facilitate communication without hindering comprehension or interaction when used between speakers of different backgrounds.

This set of 'core' features, then, becomes the key for the ELF research project. Its main point is that the ELF core would be the basis for teaching English as a lingua franca; instead of learning how 'native speakers' of English use the language, which is no longer useful knowledge in our globalising world, English language learners can instead economise their effort by learning the ELF core. This would both help them communicate in English with others in an international context and also emancipate them from the hegemonic influence of 'native speaker' norms which have dominated English language teaching for so long.

Because of the importance of specific core features for the ELF research project, it is natural that the main concern of the project becomes the source of its data. In order to sustain its theoretical and political goals, the ELF project carefully delimits its data in order to eliminate influence from native speaker English and identify the most authentic form of ELF by focusing on specific situational contexts. This is manifest in several ways. For instance, the ELF research project has primarily focused on spoken rather than written ELF communication. This is because written ELF is more likely than spoken ELF to manifest the 'confounding' influence of prescriptivist rules deriving from native speaker norms, and consequently, does not display ELF in a sufficiently "pure form" (Seidlhofer 2004).

Thus, not all forms of interaction in ELF equally count as viable data for ELF research. Clearly, the most important criterion for data inclusion is absence of native speakers. ${ }^{2}$ According to the ELF research project, data for ELF research should come from 'interactions between members of two or more different linguacultures in English, for none of whom English is the mother tongue' (Seidlhofer 2004: 211 , citing House 1999: 74). Again, this is because the presence of a native speaker is considered to 'contaminate' the data since non-native speakers might modify or adapt their otherwise 'natural' patterns of communication to take into account the presence of the native speaker. Presumably, then, the purest form of ELF is to be found in interactions involving only speakers from Kachru's Expanding Circle. An interaction in English involving a Thai and an Indonesian speaker would therefore fit the bill. An interaction between a Singaporean and a Korean would be less ideal for ELF research purposes. And finally, an interaction between an Australian and a Canadian would probably be discounted altogether.

This methodological position, however, becomes problematic when we 
consider it against a view of language that takes authenticity as an ideological construct (Bucholtz 2003). The emphasis on 'purity' presumes that there is an ELF linguistic norm that can and should be allowed to emerge unscathed once the confounding influence of the native speaker has been removed. But given the fluid and polymorphous nature of ELF (or any language, for that matter), such efforts to draw a clear boundary between native and non-native usage are not theoretically sound. To privilege one particular mode of interaction or group of speakers as more authentically representing ELF than others is clearly an unsatisfactory conceptualisation, as it ignores the complex and polymorphous way in which English is used in the world. Based on a simplistic view of ELF, it arbitra-rily assigns a particular type of using English as more central to the entire range of possible types. Moreover, such a direction does not sit well with the emancipatory goal of ELF research, as it can easily fall into the trap of imposing a hierarchical order among different ways of using English in the process of privileging particular modes of interaction as more authentic than others.

This latter point can be illustrated through a further assumption the ELF research project makes about ideal sources of data. The ELF project gives high priority to interactions involving 'expert speakers of English from a wide range of L1s' (Jenkins 2006: 169), or 'highly competent and fluent users of ELF' (Seidlhofer, Breiteneder, and Pitzl 2006: 14). This reference to 'expert', 'competent' or 'fluent' speakers of ELF would seem to rule in interactions between, say, Thai and Indonesian English language teachers or diplomats while ruling out interactions between Thai and Indonesian domestic helpers, even if the language being used in both situations is English.
And indeed, the specific kinds of speakers that ELF researchers have focused on tend to include international businessmen, employees of multinational companies, academics, university students, and English language teachers (Jenkins 2007; Mauranen 2007, 2012; Seidlhofer 2004).

The kind of English that the ELF project is interested in is, in other words, a kind of 'educated' English. That is, even as the project espouses an anti-hegemonic stance towards the native speaker/ non-native speaker dichotomy, it seems to be assuming a class-based usage of ELF; this can be glimpsed in Seidlhofer's (2004: 211) assertion that 'whatever the setting, ELF interactions often occur in influential networks (i.e., global business, politics, science, technology and media discourse ...)'.

The ELF research project does not usually explicit justify this focus on speakers from a particular class background, though we may assume it is not due to the quantitative dominance of such speakers; the large number of lower-class migrant workers in the world would arguably give rise to plenty of situations in which English is used among speakers working in less than 'influential networks'. Presumably, this covert appeal to class is necessary because practitioners of the ELF research project may wish to present the ELF usage of more privileged speakers as a model that can contest the native speaker's hegemony with greater legitimacy. At the same time, the more stable and wide-reaching social networks of elite ELF speakers may mean that their use of English could be less subject to L1 'interference' (though this assumption could be empirically assessed) but more representative of an emergent regularity distinct from native speakers' English.

However, this focus on elite speakers who carry the aura of success and socio-economic mobility is problematic 
for several reasons. For instance, it is not only conceivable but highly probable (especially in the case of English language teachers) that the 'educated' English that these ELF speakers possess will have been acquired using native speaker norms as a point of reference. That is, these speakers would have learnt English in educational contexts that are based on traditional native speaker norms, particularly since they would be coming from Expanding Circle countries, which are typically recognized as being exonormatively oriented towards the Inner Circle. Once we recognize this, then the feasibility of distilling 'pure' ELF from their language use as though their English would somehow be free of native speaker contaminants becomes highly questionable. The idea of a 'pure' ELF that is untainted by native speaker norms while also being manifested by 'expert speakers of English' seems chimerical at best.

Another problem, however, relates to the more fundamental goals of the ELF research project, and is therefore potentially more damaging. By positing socially privileged speakers as models for ELF interaction, the ELF research project risks reproducing the very problems of English that research on ELF, including the ELF research project, aims to combat. That is, if the position of an ideal speaker of ELF on whom learners should model their use of English is determined based on social and economic background, then ELF speakers without such background would still be subject to illegitimation, marginalisation, and discrimination, just because they speak differently from those privileged model speakers, and we will have simply replaced the hegemony of the native speaker with the hegemony of the elite speaker. While it is most likely the case that the advocates of the ELF research project do not intend to celebrate and rationalize the classed positions of elite non-native speakers, placing the linguistic practices of those speakers at the centre of the model for ELF leads to an unequal distribution of authority and legitimacy, and breeds the danger of doubly marginalising the less-privileged non-native speaker.

In our opinion, this problem is not simply a matter of political sensitivity (or a lack thereof), because highlighting the ELF usage of less privileged groups instead to the exclusion of privileged ones is not the answer either. The problem, instead, derives from more fundamental assumptions of the ELF research project that we outlined above. When language is understood and approached as a bounded entity (such as 'ELF'), the diversity and variation that takes place within those boundaries come to be seen as contamination and corruption that arise due to interference from the 'outside' and thus are considered to be less ideal as data. This also means that one or more groups must be seen as more representative and authentic than other users of the language, as the division of 'centre' and 'periphery' of sociolinguistic space is imposed on speakers to place them in a hierarchical relation of inequality. Thus the assumption of language as a bounded entity compromises researchers and makes it difficult for them to question and contest linguistic inequalities.

This points us to one way in which assumptions about the nature of language are closely linked with our capacity for critical engagement with the relations of power underlying language use. In the case of the ELF research project, its pursuit of an 'authentic' form of ELF inevitably leads to a search for 'authentic' speakers, who are then exalted as model ELF speakers for the rest; this serves as a window through which relations of inequality are reintroduced, undermining the potential transformative effect 
that the ELF research project may bring about in the lives of many speakers who use English in the world today.

\section{FEATURES OF ELF: THE QUESTION OF INTELLIGIBILITY}

$\mathrm{W}$ e noted above that a distinguishing strategy of the ELF research project has been to identify core ELF features that are independent of native speaker norms and that can be used to transform English language teaching practices for non-native speakers. Such a focus on core features, however, has invited much criticism, as some scholars are concerned that highlighting certain features over others may lead back to treating ELF as a monolithic variety imposed on the non-native learner. For instance, Prodromou (2008) argues:

Jenkins repeatedly conflates ELF and indigenized varieties, sliding from one to the other as if the phenomena described were of the same kind.... The "varietal" forms are treated as "monolithic" in so far as ELF users "have to" adapt their discourse to conform to these 'core' items (Jenkins 2006: 161). Thus, while denying that ELF is a monolithic model, Jenkins argues as if ELF were a variety with prescriptive norms of its own. (2008:28)

Of course, the main proponents of the ELF research project strongly deny such charges, arguing that identification of the ELF core is a necessary tool for describing the diverse and polymorphous nature of English as an international language, and that learners always have the agency to decide which form of English they will acquire (Jenkins 2007 Ch.1; Seidlhofer 2006). However, a closer inspection of the way in which the focus on the ELF core has featured in the ELF research project points to problems which cannot be simply considered outcomes of methodological necessity or addressed through pedagogical flexibility.

So far, the ELF project has identified core features in the areas of phonology, lexicogrammar, and pragmatics. Jenkins (2000) has done influential work on phonology, which distinguishes between phonological features of English that are part of the 'Lingua Franca Core' (LFC) and those which are not; the former refers to features that critically affect the intelligibility of pronunciation whereas the latter refers to features that do not seriously lead to intelligibility problems. Examples of the LFC include contrast in vowel length and placement of nuclear stress, both of which seriously affect intelligibility if not maintained. In the case of lexicogrammar, Seidlhofer (2004; see also Prodromou 2008: 31) suggests the following grammatical features as noncore, for they present 'no obstacle to communicative success' (220):

i. simple present third person: He look angry

ii. article omission: He bought new car

iii. using a bare infinitive in place of ing: He look forward to buy new car

In the case of pragmatics, while it is generally considered too early to establish a clear distinction between core and noncore 'pragmatic principles', ELF advocates have suggested the following as key characteristics of ELF interaction (from Seidlhofer 2004: 218):

i. Misunderstandings are not frequent in ELF interactions; when they do occur, they tend to be resolved either by topic change or, less often, by overt negotiation using communication strategies such as rephrasing and repetition.

ii. Interference from L1 interactional norms is very rare - a kind of 
suspension of expectations regarding norms seems to be in operation.

iii. As long as a certain threshold of understanding is obtained, interlocutors seem to adopt what Firth (1996) has termed the 'let-it-pass principle', which gives the impression of ELF talk being overtly consensus-oriented, cooperative and mutually supportive, and thus fairly robust.

The ELF research project's focus on the distinction between core and non-core features illustrates its emphasis on intelligibility. From that emphasis, we can see the underlying language-ideological stance that characterizes the project - that is, as long as speakers can mutually understand each other, communication is deemed successful. For instance, while the lexicogrammatical features above would generally be characterized as 'non-standard', if not downright 'ungrammatical', Seidlhofer et al. (2006: 17; also see Prodromou 2008: 31) quote an ELF user as saying 'what really matters is that we are sort of basically understood', thereby defending their usage as practical. This, of course, is the whole political point about the ELF project: stigma and prejudice to which non-native speakers' English is frequently subjected should be rejected, for ELF as used by those speakers is perfectly pragmatic and practical, fully and effectively able to facilitate communication across cultures.

Despite such laudable intent, however, there are several problems with the underlying assumptions here. First of all, this represents a particular language ideology that deems transfer of referential information as central to communication. The phonological LFC, for instance, which mainly focuses on segmental features, implies that the notion of intelligibility concerns recognition and identification of words as they are pronounced.
However, we may argue that this is an unnecessarily narrow conceptualisation, as what is often simply referred to as 'intelligibility' may be distinguished into three components (Smith 1988; Smith and Nelson 1985): intelligibility (in the narrow sense of word recognition), comprehensibility (how an utterance or text is linguistically meaningful), and interpretability (how the utterance or text can be understood in relation to particular goals or intentions). Also significant in the process of communication would be the recognition, interpretation, and negotiation of indexical meaning as well - that is, how participants in interaction not only make sense of referential and discursive meaning, but also of social meaning, by being able to position the speaker and her discourse within a field of social relations and positions.

The narrow view of intelligibility is again linked with a perspective that treats language as an abstract, bounded system. The view that treats variation and hybridity as problematic noise results in an understanding of language as a fixed code, which can be detached from its social context of use for easy description in terms of formal features. Based on such an assumption, communication is reduced to conveyance of referential meaning, and the complex work of social positioning and negotiation that participants carry out through interaction is ignored. This can be a significant problem for research on ELF, because it not only misses the entire process of identity work involved in ELF interaction, but also leads to underestimating the tenacity of ideological forces that non-native speakers must work against when they speak in English - forces that are not necessarily lifted when the interaction takes place among non-native speakers.

Cameron (1995) has pointed out how speaking 'ungrammatically' is not 
simply a matter of language, as it can often carry various kinds of indexical connotations such as being stupid, unintelligent or even immoral. For instance, because the lexicogrammatical constructions mentioned above are generally considered ungrammatical, there is a risk of the speakers being burdened with various kinds of social stigma, even when they are communicating with non-native speakers. But this problem tends to be overlooked in the ELF research project, as we can see from the ELF project's characterisation of ELF pragmatics as fully cooperative and mutually supportive.

A good example of the limitation of cooperativeness in ELF interaction comes from Meeuwis (1994), who describes interactions involving South Korean, Tanzanian and Flemish engineers. ${ }^{3}$ The South Koreans and the Tanzanians were junior engineers, who had been sent to Belgium to attend a training program, conducted in English by the Flemish engineers (1994: 394). Here we have a communicative situation that clearly fits the ideal model for the ELF research project; the speakers all come from backgrounds and cultures where English is not a first language, and they are involved in using English for 'practical' purposes, and they are all educated professionals.

Meeuwis, however, points out that there were greater communication problems between the Tanzanians and their Flemish instructors than between the South Koreans and the same instructors. Meeuwis describes these differences in terms of communicative 'testiness' and 'leniency': there was greater testiness in the Tanzanian-Flemish interactions whereas the South Korean-Flemish interactions were characterised by greater leniency. This is despite the fact that:

the Tanzanians' English deviated to $a$ far lesser extent from what the Flemish are used to as a standard English than the Koreans' English did. The Koreans' English showed many more sources for potential breakdowns and for the development of these breakdowns into conflicts.

The interactions between the Flemish and Tanzanians, whose non-native discourse, as noted, showed even less potential causes for communicative problems, were marked by a much lower degree of communicative leniency on behalf of the Flemish. Occasional pragmatic differences and breakdowns were selectively highlighted ... [The Flemish instructors'] commentary that this interactive behavior irritated them points in the direction of communication "conflict".

(Meeuwis 1994: 400-1, italics added)

Meeuwis explains that this difference in the distribution of 'testiness' and 'leniency' is attributable to the dominance of publicly held stereotypes about different nationalities and the traits they are likely to possess (1994: 402):

A dominating Belgian and Western European public opinion still holds to a deeply-rooted perception of Africans as intellectually retarded, underdeveloped, uncivilized in manners and social conduct, and poor in cultural history and achievement. The Far East, on the other hand, typically enjoys fame as possessing an ancient cultural, intellectual, and artistic tradition.

Meeuwis' observations concerning communicative 'leniency' (or lack therefore) go to the very heart of the ELF project's claims about intercultural pragmatics, particularly its claims about the prevalence of the 'let-it-pass' principle. As Meeuwis points out (1994: 398, italics in original): 
First, it cannot be concluded from the findings that leniency is typical of NNS-NNS communication with respect to all levels of linguistic structuring ... Second, I would not claim that NNS-NNS intercultural communication is invariably characterized by participants' leniency ... conditions of the extra-situational order, such as structural inequality and historically institutionalized prejudice, are able to override leniency in NNS-NNS conversations.

The ELF research project's broad assertion that ELF interaction is guided by a 'let-it-pass' principle thus fails to take into account the kinds of cultural influences, including cultural stereotypes and attitudes, that interlocutors bring with them to each and every communicative situation. This mistake on the part of the ELF project is encouraged by envisaging ELF as a bounded, asocial entity that is characterisable through formal features that communicate referential content. It is this view of language that leads the project to presume that culture-specific influences are minimal, if not altogether absent-and that the primary concern for ELF research should therefore be ensuring intelligibility in the narrow sense. This, in turn, results in an inability to account for, or even recognize, the relations of inequality that are unambiguously present in ELF interaction. The language ideological assumptions behind the feature-based, core approach of the ELF research project, then, has the inherent danger of forgetting about the social and cultural constraints on communication that are not always smoothly dealt with in interaction among people from different cultures and societies.

\section{IMPLICATIONS FOR STUDYING LANGUAGE AND MOBILITY}

$\mathrm{T}$ the sections above, we focused on two 1 major problems with the ELF research project, and discussed how they are linked to underlying assumptions that treat language as a fixed and bounded entity. While it is clear that such assumptions about language are problematic in any case, the fact that ELF is a phenomenon located in the context of mobility makes such assumptions particularly more problematic. That is, the diversity, fluidity, and friction inherent in ELF force us to resist views of language that rely on homogeneity, fixity, and unproblematic stability.

In using English for international communication in the context of heightened mobility, there are too many different specific situations involved, with each situation likely to involve different individual speakers. Recurrent interactions involving speakers with the same background and the same situations are far too infrequent - especially if we trying to draw them from a heterogeneous collection of interactions at the global level. In this sense, ELF cannot be understood as based on a single, homogeneous, clearly delineable community, and cannot be seen as a language variety that is definable and distinguishable through a fixed set of linguistic features. As Mollin (2007: 45, cited in Maley 2008: 6) points out:

Crucially, ELF situations have the frequent attribute of occurring between ever new conversation partners, so that its speaker community is constantly in flux rather than remaining stable and fixed. A user of English as a lingua franca thus has to accommodate to different other speakers from different linguistic and cultural backgrounds with different levels of 
competence in each speech situation. It is difficult to imagine how a negotiation towards a common standard in all of these ever-changing conversation situations would proceed. Common features in ELF would thus be rather surprising.

The relations between ELF speakers are not only in constant flux, but they also are in constant interaction with the complex dynamics of power which permeates mobility itself. The ELF research project's assumption that interaction among ELF users will largely be smooth and cooperative ignores the logic of capital conversion within and across linguistic markets (Bourdieu 1991). It is widely recognised that language can act as a gatekeeper precisely because it allows selective access to social goods and affects one's social trajectory. The discussion of Meeuwis' work above shows how the ability of speakers to convert linguistic capital into some form of symbolic profit can be enhanced or undermined by the influence of cultural stereotypes, even when all the interlocutors involved are non-native speakers.

Even so-called native speakers are not exempt from the need to deal with the consequences of having devalued linguistic capital in the context of mobility (Lippi-Green 1997). Consider the experience of Helen, a Manchester woman who found her accent to be a problem when it came to employment opportunities in London (Milroy and Milroy 1999: 152153). In Helen's own words:

$\ldots$ in the arts where no-one has a regional accent ... my CV was good enough to get me interviews, but ... as soon as they heard me speak ... I wasn't taken seriously ... People can't see further than my voice and assume I'm aggressive and common. They think I should own pigeons and have an outside toilet.
Such problems of capital conversion are much more pronounced on a global level. Blommaert (2003) discusses a handwritten letter from Victoria, the 16-year-old daughter of a family that he stayed with during field trips to Tanzania. The girl is 'definitely a member of the local middle class, a class which uses proficiency in English as an emblem of class belonging ... It is, in other words, an 'expensive' resource in Dar es Salaam' (Blommaert 2003: 617). Blommaert (2003: 618-9) points out that while the text may be considered a representative of 'good English' in the local linguistic market, when this same text is moved to a different market, it loses the social indexicalities of prestige:

...as soon as the document moves across the world system and gets transplanted from a repertoire in the periphery to a repertoire in the core of the world system, the resources used by Victoria would fail to index elite status and prestige.... The indexicalities of success and prestige, consequently, only work within a local economy of signs, that of Tanzania, an economy in which even a little bit of English could pass as good, prestige-bearing English ...

Notice that the problems faced by Helen and Victoria regarding their uses of English have little to do with intelligibility in the narrow sense assumed by the ELF project. It is not that Helen was unable to make herself understood; rather, her problem was that she was perceived as lacking sufficient sophistication to warrant the kind of job that she was looking for. In fact, when Helen did finally land a job, it was with a community theatre project where 'she was told she'd only been selected because the area would benefit from a common touch' (Milroy and Milroy 1999: 152). Similarly, Victoria's act of letter writing constitutes a form of 'language display,' where the goal involved 
'constructing a relational identity of a 'good girl', someone who behaves and performs well, is probably among the best pupils of her age-group, and is worthy of compliments from her European Uncle' (Blommaert 2003: 618). But this is not sufficient for Victoria's English to allow her to overcome the kinds of social values attached to it once it leaves its original linguistic market.

As an alternative to the assumption of language as a fixed, bounded entity, we might adopt the view of language as local practice (Pennycook 2010), in which language is an outcome of flexible adoptions and appropriations of resources rooted in people's practices - including not only linguistic ones, but also social, material, and ideological ones. From this perspective, ELF may be better construed as a context of use, instead of a bundle of structural features that constitute a linguistic variety that is extractable from the behavior of authentic speakers. That is, the notion of ELF would have to refer to a repertoire of practices that speakers employ in navigating through a multiplicity of specific contexts where speakers coming from different linguistic and cultural backgrounds attempt to use English as a shared means of communication.

Here, it might be useful to consider Levinson's (1992) notion of an activity type. An activity type, according to Levinson, refers to 'a fuzzy category whose focal members are goal-defined, socially constituted, bounded, events with constraints on participants, setting, and so on, but above all on the kinds of allowable contributions. Paradigm examples would be teaching, a job interview, a jural interrogation, a football game, a task in a workshop, a dinner party, and so on' (1992:69, emphasis in original). Activity types are important because they draw our attention to the question of how the structure of the activity constrains the kinds of text and talk that can or should be employed during the conduct of the activity.

ELF interactions, we suggest, may represent a particular class of activity types, one where the goal involves the need to communicate in a situation where none of the participants share the same L1. In such a situation, ease of understanding and shared norms of interpretation involving the same code cannot be taken for granted. Uncertainties that permeate such contexts may lead to complex outcomes. On the one hand, the participants may be acutely aware that, precisely because they do not belong to the same speech community, they need to make special allowances when interacting with each other, thus leading to greater flexibility and creative appropriations of English. On the other hand, again due to such uncertainties, they may rely on more dominant ideological preconceptions of the Other imagined in terms of hierarchical relations, and use that to interpret the meaning and value of others' use of English (Park and Wee 2009). In this sense, ELF use as an activity type may be seen as a tension-ridden space, where the kinds of pragmatic features postulated by the ELF project - the use of repetition, the 'let-it-pass principle' -are employed alongside language ideologies that link different uses of English with different social meanings. If so, it may be difficult to see immediately how a recurrent, distilled pattern of language use may emerge as a result of such practices, and this may indeed be the point of ELF interaction - that its speakers are constantly negotiating the way in which they use English to position themselves in relation to each other while also negotiating referential meaning they are trying to communicate. 
Viewing ELF as an activity type, then, leads us away from a focus on English, since the same strategies might be observed whenever speakers who lack a shared linguistic or cultural background are attempting to communicate, regardless of whether they use English or some other language as the lingua franca. In this sense, treating ELF as an activity type bleeds ELF of its distinctiveness as a research project, leading us towards the more general objective of promoting cross-cultural meta-communicative awareness and sensitivity. ${ }^{4}$ Various scholars have in fact been calling for education initiatives that specifically aim at nurturing such cross-cultural awareness and sensitivity. This is a goal that many argue is increasingly urgent given the challenges of living a globalised world (see, for example, the contributions to Suárez-Orozco 2007). Thus, Süssmuth (2007: 210) laments the 'lack of didactic concepts for adequately incorporating intercultural skills in schools', and Mansilla and Gardner (2007: 58) emphasize the importance of cultivating 'global consciousness'.

However, the use of English across speakers who do not share a common language or culture would still remain an important area for research on crosscultural communication, because the status of English as a global language gives great ideological salience to the hegemonic hierarchy of native vs. non-native accents that are linked with national and social identities (Park and Wee 2009). That is, studying the use of English in international communication is an excellent site for understanding how cross-cultural awareness can never simply transcend relations of power that constrain experiences of mobility and social life in general: inequalities of English constantly remind us that communication across cultures, particularly when it is mediated by English, cannot be a neutral ground where anyone may participate equally with minimal trouble. In fact, without such sensitivity to issues of power and inequality, research and advocacy that aim to inculcate awareness of intercultural skills and global consciousness in the student can run into the exact same problem as the ELF research project, unwittingly downplaying the unequal relationships of power that such students will always be a part of.

The ELF research project, then, would do well to actively reconsider some of its fundamental assumptions, and use this as an opportunity to push its original goal of moving the centre of English even further. The focus on linguistic features may be shifted toward practices, so that ELF is understood less as a variety existing independently of social conditions, and more as what people do when they engage in communication across cultures, and how they deal with (or fail to deal with) ideologies that maintain and reproduce cultural and linguistic boundaries. Also, the ELF research project may relax its emphasis on 'pure' data that are not 'contaminated' by native speakers or 'interference' from the English of socially less-privileged speakers, instead making such complex patterns of interaction one of its foci of analysis. Such an approach would not only have the benefit of not reifying the non-native/native speaker distinction and its connection to class, but could also allow the ELF project to more actively study and analyse how relations of power can shape and condition speakers' practices in cross-cultural communication. This would help the project to develop more precise and sophisticated views of how to spread the idea that, in an increasingly complex cultural world, the responsibility for becoming more appreciative and aware of the importance of cross-cultural accommodation lies with 
everybody, native and non-native speakers of English alike. Such changes in direction would allow us to fully explore the significance of the phenomenon of ELF for language and mobility in our global world.

\section{ENDNOTES}

${ }^{1}$ This paper is a revised version of Park and Wee (2011). We wish to thank Wiley-Blackwell and the editors of World Englishes for permission to reproduce significant portions of that article.

${ }^{2}$ Of course it is not the case that ELF research never includes data involving native speakers. For instance, an anonymous reviewer suggests Mauranen's ELFA (English as a Lingua Franca in Academic Settings) project on English use in Finnish universities as a study that includes native speakers. However, we wish to point out that the exclusion of native speakers represents a methodological desideratum for ELF rather than a criterion that is always met in specific research projects. This is actually borne out in the ELFA project's description, which states that native speaker speech constitutes $5 \%$ of the overall data and 'long monologues (e.g. conference presentations or course lectures) by native speakers of English are not transcribed, but if English native speakers are present in groups, this is coded' (http:// www.helsinki.fi/englanti/elfa/elfacorpus.html; accessed 22 November 2012). In other words, the preference is still for the exclusion of native speakers, where possible.

${ }^{3}$ We thank Graham Jones for drawing our attention to Meeuwis' work.

4 This is an issue that ELF still needs to come to terms with. Björkman's (2011) discussion of pragmatic strategies used in an educational setting represents a useful step in this direction. However, while she acknowledges that the strategies she identifies (such as backchannelling, prospective and retrospective signaling of the discourse structure, and repetition) may be considered general, she still on occasion characterizes them as strategies for 'ELF usage' $(2011,962)$.

\section{REFERENCES}

Björkman, Beyza. 2011. Pragmatic strategies in English as an academic lingua franca: Ways of achieving communicative effectiveness? Journal of Pragmatics 43(4): 950-964.

Blommaert, Jan. 2003. Commentary: A sociolinguistics of globalization. Journal of Sociolinguistics 7(4):607-23.

Bourdieu, Pierre. 1991. Language and Symbolic Power. Cambridge, Mass.: Harvard University Press.

Bucholtz, Mary. 2003. Sociolinguistic nostalgia and the authentication of identity. Journal of Sociolinguistics 7 (3): 398-416.

Canagarajah, Suresh. 2007. Lingua franca English, multilingual communities, and language acquisition. Modern Language Journal 91: 923-939.

Cameron, Deborah. 1995. Verbal Hygiene. London: Routledge.

Crystal, David. 1988. The English Language Today. London: Penguin.

Crystal, David. 2003. English as a Global Language. Cambridge: Cambridge University Press.

Firth, A. 1996. The discursive accomplishment of normality. On 'lingua franca' English and conversation analysis. Journal of Pragmatics 26: 237-59.

House, Juliane. 1999. Misunderstanding in intercultural communication: Interactions in English as a lingua franca and the myth of mutual intelligibility. In C. Gnutzmann (ed.). Teaching and Learning English as a Global Language. Tübingen: Stauffenburg. 73-89.

House, Juliane. 2002. Pragmatic competence in lingua franca English. In K. Knapp and C. Meierkord (eds). Lingua Franca Communication. Frankfurt: Lang. 245-67.

House, Juliane. 2003. English as a lingua franca: A threat to multilingualism? Journal of Sociolinguistics 7(4): 556-78.

Jenkins, Jennifer. 2000. The Phonology of English as an International Language. Oxford: Oxford University Press.

Jenkins, Jennifer. 2006. Current perspectives on teaching world Englishes and English as a lingua franca. TESOL Quarterly 40(1): 157-181. 
Jenkins, Jennifer. 2007. English as a Lingua Franca: Attitude and Identity. Oxford: Oxford University Press.

Kirkpatrick, Andy. 2010. English as a Lingua Franca in ASEAN. Singapore: NUS Press.

Levinson, Stephen.1992. Activity types and language. In Paul Drew and John Heritage (eds). Talk at Work: Interaction in Institutional Settings. Cambridge: Cambridge University Press. 66-100. [Originally published in Linguistics 17:356-99.]

Lippi-Green, Rosina. 1997. English with an Accent. London: Routledge.

Maley, Alan. 2008. The reality of EIL and the myth of ELF. Paper presented at GlobEng. University of Verona, Italy, 14-16 February 2008.

Mansilla, V. B. and H. Gardner. 2007. From teaching globalization to nurturing global consciousness. In M. M. Suárez-Orozco (ed.). Learning in the Global Era. Berkeley, CA.: University of California Press. 47-66.

Mauranen, Anna, 2007. Hybrid voices: English as the lingua franca of academics. In K. Flottum (ed.). Language and Discipline Perspectives on Academic Discourse. Newcastle: Cambridge Scholars Publishing. 243-259.

Mauranen, Anna. 2012. Exploring ELF: Academic English Shaped by Non-native Speakers. Cambridge: Cambridge University Press.

Meeuwis, M. 1994. Leniency and testiness in intercultural communication: Remarks on ideology and context in interactional sociolinguistics. Pragmatics 4(3):391-408.

Milroy, James and Lesley Milroy. 1999. Authority in Language: Investigating Standard English. London: Routledge.

Mollin, Sandra. 2007. English as a lingua franca: A new variety in the new expanding circle? Nordic Journal of English Studies 5 (2): 41-57.

Park, Joseph Sung-Yul, and Lionel Wee. 2009. The three circles redux: A markettheoretic perspective on World Englishes. Applied Linguistics 30 (3):389-406.

Park, Joseph Sung-Yul, and Lionel Wee. 2011. A practice-based critique of English as a lingua franca. World Englishes 30 (3): 360-374.

Pennycook, Alastair. 2010. Language as a Local Practice. London: Routledge.

Phillipson, Robert. 1992. Linguistic Imperialism. Oxford: Oxford University Press.

Prodromou, Luke. 2008. English as a Lingua Franca. London/New York: Continuum.

Seidlhofer, Barbara 2001. Closing a conceptual gap: the case for a description of English as a lingua franca. International Journal of Applied Linguistics 11:133-58.

Seidlhofer, Barbara. 2004. Research perspectives on teaching English as a lingua franca. Annual Review of Applied Linguistics 24:209-239.

Seidlhofer, Barbara. 2005. Key concepts in ELT: English as a lingua franca. ELT Journal 59 (4): 339-41.

Seidlhofer, Barbara. 2006. English as a lingua franca in the expanding circle: What it isn't. In Rani Rubdy and Mario Saraceni (eds). English in the World: Global Rules, Global Roles. London: Continuum. 40-50.

Seidlhofer, Barbara, A. Breiteneder and M-L Pitzl. 2006. English as a lingua franca in Europe. Annual Review of Applied Linguistics 26:3-34.

Smith, Larry E. 1988. Language spread and issues of intelligibility. In P. Lowenberg (ed.). Language Spread and Language Policy: Issues, Implications and Case Studies. Georgetown University Roundtable on Languages and Linguistics 1987. Washington D.C.: Georgetown University Press. 265-282.

Smith, Larry E. and Cecil L. Nelson. 1985. International intelligibility of English: Directions and resources. World Englishes 4 (3): 333-342.

Suárez-Orozco, M. M. (ed.). 2007. Learning in the Global Era: International Perspectives on Globalization and Education. Berkeley: University of California Press.

Süssumuth, R. 2007. On the need for teaching intercultural skills: Challenges for education in a globalizing world. In M. M. Suárez-Orozco (ed.). Learning in the Global Era. Berkeley, CA.: University of California Press. 195-212. 